\title{
EL TERREMOTO DEL BICENTENARIO, VIRTUDES REPUBLICANAS E INSTITUCIONES PÚBLICAS. UNA REFLEXIÓN DESDE LA HISTORIA DE LA CIUDAD DE CONCEPCIÓN
}

\author{
Sergio Micco Aguayo (sergio.micco@iap.uchile.cl) \\ Instituto de Asuntos Públicos - Universidad de Chile
}

En el ensayo se argumenta que el terremoto de febrero de 2010 retrotrajo el debate público a las reflexiones de nuestros padres fundadores sobre las virtudes públicas y el interés general. Por esto que el trabajo se propone, a la luz de la teoría política y de la experiencia histórica chilena, repasar algunas de estas cuestiones. Según el autor, el contar con instituciones públicas asentadas en una poderosa Constitución política y promover las virtudes públicas mediante la educación y los medios de comunicación social, es especialmente vital cuando las repúblicas sufren graves trastornos, sociales o naturales.

Palabras Clave: terremoto; republicanismo; instituciones; Concepción; Chile. 


\title{
THE EARTHQUAKE OF THE BICENTENARY: REPUBLICAN VIRTUES AND PUBLIC INSTITUTIONS. A REFLECTION FROM THE HISTORY OF THE CITY OF CONCEPCION
}

\begin{abstract}
This essay argues that February 2010 earthquake evoked our founding fathers' reflections on the public interest and virtues. It is necessary to review some of these questions in view of political theory and the Chilean historical experience. The establishment of public institutions founded on a powerful and legitimized constitution which is legitimized in the public, and the promotion of public virtues through education and the media and shown to be particularly important for societies facing social or natural crises.
\end{abstract}

Keywords: earthquake; republicanism; institutions; Concepción; Chile. 


\section{INTRODUCCIÓN}

El terremoto del 27 de febrero desnudó no sólo las precariedades físicas de nuestro territorio natural sino que además develó aspectos de la condición humana y de la convivencia cívica chilena que en condiciones normales no nos gustan admitir. Ello ocurrió además en el año en que un orgulloso Chile se aprestaba a celebrar su Bicentenario. Acabábamos de ser recibidos en el club de los países desarrollados del mundo (OCDE) y de repente el piso se nos movió entero y profundas grietas aparecieron en el rostro nacional.

Cuando se desató la furia del terremoto del 27 de febrero del 2010 y al día siguiente pudimos observar sus efectos devastadores, era obvio que estábamos frente a un hecho histórico. Más que la magnitud de la destrucción física, nos sorprendió a todos cómo los saqueos y pillajes se extendieron. Los medios de comunicación social destacaron especialmente lo ocurrido en la provincia de Concepción. Esas escenas no podían ser más dolorosas para quienes venimos de esas tierras en que se libró buena parte de la guerra de Independencia y se asentó sólidamente el espíritu laico de servicio público. El pensamiento conservador arremetió con fuerza y recordó aquello que el hombre, en estado de naturaleza, es "Homo homini lupus".

Por cierto, no se trata de un defecto de los chilenos. Leo al pasar que un 29 de mayo del año 526 un devastador terremoto destruyó Antioquía, la tercera ciudad del Imperio Romano, murieron unas trescientas mil personas, muchas de ellas de hambre, desangradas bajo los escombros o bajo la acción de los saqueadores. Tras el terremoto de Yokohama del año 1703, turbas de enfurecidos japoneses las emprendieron contra los coreanos, a quienes responsabilizaron de los saqueos, muriendo linchados centenares. La policía aprovechó también de matar a políticos acusados de aprovecharse del terremoto para promover la caída del gobierno. No en vano Mao sostenía: "Estad preparados para la guerra y los desastres naturales". De hecho, murió el año 1976, seis semanas después del horrible terremoto de Tangshan del 28 de julio en el que murieron cientos de miles de personas (Withington, 2009: 45). 
No nos debe extrañar que tras los primeros saqueos ocurridos en la madrugada del 28 de febrero, se impusieran los llamados al toque de queda y a la salida de los militares a la calle. Las invitaciones a disparar a matar vinieron de tirios y troyanos ${ }^{1}$. Lo extraordinario del asunto es que veníamos saliendo de una elección presidencial en la que los tres candidatos compitieron por demostrar ante la opinión pública quien era más progresista. Tras el terremoto parecían haber desaparecido como por arte de magia los liberales respetuosos de los derechos individuales, los progresistas radicales a lo Rousseau que confían en la bondad natural del hombre y los republicanos de las virtudes públicas. Un incómodo silencio se extendió. En inesperado giro ese silencio se dirigió en contra del pensamiento y lo llamó a la acción. ¿No tendría algo que decir la teoría política normativa? La inquietud aumentó cuando a la imposición del orden público y tras el desconcierto inicial, comenzó a hablarse de responder a la emergencia de los damnificados y a la tarea de la reconstrucción nacional. Los políticos y economistas empezaron a debatir acerca de la forma de reconstruir el país y de los métodos de financiamiento. Aquí nuevamente se nos empezaron a colar distintas concepciones del ser humano -utilitaristas y altruistas- y diferentes visiones ideológicas - mercantilistas, estatistas o mixtas-.

Me pareció especialmente significativo que el terremoto y el subsecuente debate se produjera exactamente doscientos años después del inicio del proceso de independencia nacional. Este fue el terremoto del Bicentenario y nos retrotrajo, como lo intentaré demostrar, a las reflexiones de nuestros padres fundadores acerca de las virtudes públicas y el interés general.

1 Autoridades locales de izquierda y derecha compitieron a través de la radio local en llamar a los militares. Algunos señalaron que si era necesario, que dispararan a matar. Una psiquiatra me relató la reunión de vecinos de su comunidad en que la dirigente que resumió los acuerdos aclaró que en caso de presentarse una turba, la instrucción de Carabineros de Chile era disparar a la cabeza de los maleantes, lo que obviamente era falso. Lo espeluznante del asunto es que la gente aplaudió al escuchar esta insólita instrucción. Cinco días después de ocurrido el terremoto pude recorrer las calles de Concepción y Talcahuano. Las barricadas impedían el acceso a los barrios y comités de autodefensa vecinales habían surgido por doquier. Todos armados con palos, cuchillos y rifles expresaban un hondo temor al "otro" que desde las poblaciones pobres se abalanzaría para arrebatar la propiedad de los angustiados vecinos. Fue la respuesta al fracaso del Estado de imponer el orden y la ley inmediatamente tras el terremoto. 
Por cierto, hay otros aspectos que los terremotos sacan a la luz del mediodía del intelecto humano. Me refiero a la reflexión teológica y filosófica acerca del mal físico. ¿Cuál es la causa final y el sentido último de terremotos, maremotos, diluvios y cataclismos que destruyen vidas inocentes? El debate es viejo como la humanidad misma. Teorías recientes señalan que hace unos setenta y cuatro mil años, se produjo una inmensa erupción volcánica, en el actual lago Toba, en la isla indonesia de Sumatra. La cuestión es que se ha calculado que la población humana de esos tiempos, estimada en un millón de personas, se redujo a solo diez mil (Withington, 2009:15). Por ello, desde Epicuro la pregunta está planteada: si hay un dios omnipotente y bueno, ¿cómo es posible que permita que estas cosas ocurran? No se trata de un debate teórico, sino que existencial. Plinio el joven, relatando la destrucción de Pompeya y Herculano, cuenta que en medio de una oscuridad espantosa estuvo a punto:

de ser arrollado por una multitud cada vez más densa que huía chillando y lamentándose: 'unos llamaban a gritos a sus padres, otros a sus hijos, otros a sus esposas o maridos... muchos alzaban las manos al cielo, implorando a los dioses, pero eran más quienes decían que ya no había dioses, y que aquélla era la última noche del mundo' (Withington, 2009: 21).

Esta pregunta llevó a Voltaire, ante el terremoto de Portugal de 1755, a la crisis filosófica y de fe más profunda que se expresaron en "Cándido" y su "Poema sobre el desastre de Lisboa”. Agrego que en caso de cataclismos como el terremoto del bicentenario, y ante las miserables reacciones que provocó, no es raro que resurja otro debate filosófico y antropológico, de hondas consecuencias políticas.

Pienso en las reflexiones acerca de esa otra clase de mal, ya no el físico, sino que el mal moral ${ }^{2}$. Nos referimos a ese mal que desata el ser humano cuando mata, viola, roba, hurta, saquea impúdicamente. Pareciera ser que surge lo peor de nosotros cuando sabemos que nuestros delitos no serán conocidos o en contextos en que todos parecen perpetrarlos. Platón relató en el mito de Giges cómo un bondadoso

2 Así como el libro de John Withington nos relata la historia de distintas formas del mal físico de terremotos, maremotos, erupciones volcánicas, etc., Jean Delumeau (2002) ha escrito una historia de Occidente a partir del miedo al otro. 
campesino al servicio del rey de Lidia, al descubrir que un anillo lo hacía invisible, se convirtió en un feroz delincuente seduciendo a la reina, para luego con su complicidad atacar y matar al rey, "tomando posesión del poder" (República, II, 360 b). No menos pesimista fue Freud en su "Malestar de la cultura", tras la Primera Guerra Mundial que inició la gran guerra civil europea que terminó en 1945 con un saldo de decenas y decenas de millones de muertos.

Como se ve, los cataclismos naturales y sus consecuencias fuerzan al pensamiento a ponerse en movimiento. De ahí que surgió este ensayo que aborda algunas de estas cuestiones a la luz de la teoría política y de la experiencia histórica chilena. Me refiero al debate acerca de la condición humana y de la influencia de dicha deliberación en la configuración de las instituciones políticas. Agrego además la cuestión de la importancia de las virtudes públicas que pueden llevar al heroísmo en caso de desastres naturales, disturbios civiles y guerras internacionales ( $\mathrm{y}$ en su defecto mostrar el feo rostro del individualismo ilustrado hasta el salvaje expresado en el pillaje, acaparamiento, especulación en bienes raíces, elevación abusiva de precios, etc.). Finalmente quiero volver sobre el viejo tema de la necesidad de pensar en instituciones que fomenten dichas virtudes: educación, medios de comunicación social e instituciones políticas legítimas y eficaces (y que en su ausencia nos develan capital social negativo, sensacionalismo comunicacional, desconfianza entre las Fuerzas Armadas y la clase dirigente de una democracia y precariedad de la administración pública).

En suma, el ensayo contiene cuatro partes. En la primera, desde la teoría política, se relata acerca del debate entre conservadores, republicanos y liberales; para luego llevar ese debate al Chile de 1810; en la tercera parte se da cuenta de la historia de Concepción y la naturaleza chilena "heroico-trágica"; por último y a modo de síntesis, se reflexiona sobre virtudes republicanas en tierra de volcanes y terremotos.

\section{CONSERVADORES, REPUBLICANOS Y LIBERALES}

Antes de hablar de los republicanos y liberales, partamos por los quienes, tras el terremoto del bicentenario, hegemonizaron la esfera pública al reclamar orden, incluso sin ley. Bárbara Goodwin señala que es extraordinariamente difícil definir 
qué es un conservador. Se trata más de un hábito y de una forma de ser, que una teoría. Sin embargo, arriesga un juicio y señala que entre otras cosas su visión del hombre no es positiva. Lo considera un ser caído y que tiende al mal, como el río desemboca en el mar. Los seres humanos somos débiles, egoístas, irracionales (Goodwin, 1997: 188). De ahí el papel del Estado, su burocracia, ejército y policía en la imposición del orden social vía la ley y el orden público. Ciertamente que existe una relación fuerte entre las políticas conservadoras y una concepción de la condición humana como un ser malvado y corrompido.

Por lo dicho en el párrafo anterior los saqueos en Concepción no hubiesen sorprendido al buen conservador de Hobbes. En De Cive expresa que todo hombre, en el estado de naturaleza, anterior a la sociedad civil, tiene derecho a conservarse, utilizando todos los medios necesarios a su alcance.

Así, entonces, cada cual tiene derecho para hacer y poseer todo aquello que juzgue conveniente para su conservación. Y, en consecuencia, la justicia o injusticia de una acción depende del juicio de aquel que la ejecuta; juicio que lo margina de toda condena y que justifica su proceder. Todo esto en un estado puramente natural (Godoy, 1986: 16).

Las consecuencias de este mundo en que todos ejercen justicia por mano propia es famosa: "Y, lo peor de todo, el miedo perpetuo a la muerte, y la vida del hombre, una vida solitaria, pobre, hosca, embrutecida y breve" (Hobbes citado en Strauss, y Cropsey, 1996: 381).

Contra esta concepción se opone Jean Jacques Rousseau, el campeón del progresismo. En su "Discurso sobre el origen y los fundamentos de la desigualdad entre los hombres" reclama en contra de Hobbes. Lo acusa de concebir al hombre como un ser naturalmente malo, vicioso, egoísta, que cree no deberle nada a sus semejantes y que por el contrario es único propietario de todo el universo. Le reprocha que el hombre no nació así, sino que fue convertido en eso por la sociedad. Como sabemos, para el ginebrino es el nacimiento de la propiedad privada lo que genera la sociedad civil; rompiendo la natural libertad, igualdad e inocente armonía primigenia del buen salvaje. Volvamos a leerlo: 
El primero que, habiendo cercado un terreno, se le ocurrió decir: Esto es mío, y encontró gentes lo bastante simples para creerlo, ése fue el verdadero fundador de la sociedad civil. ¡Cuántos crímenes, guerras, asesinatos, cuántas miserias y horrores no habría evitado al género humano aquel que, arrancando las estacas o allanando el cerco, hubiese gritado a sus semejantes: "Guardaos de escuchar a este impostor; estáis perdidos si olvidáis que los frutos son de todos y la tierra no es de nadie" (Miranda, 1997: 333).

Entonces son los vicios que trae la sociedad los que malogran al buen salvaje y nada bueno llegará con el primer contrato social propuesto por un astuto rico a sus tontos vecinos. Se requiere un nuevo contrato social que jacobinos, girondinos, mencheviques y bolcheviques intentarán estructurar a partir de 1789.

Para Thomas Hobbes detrás de los saqueos y de los angustiosos llamados al toque de queda y a asumir la legítima defensa de lo propio se esconde el ser humano en su horror a volver al estado de naturaleza. Ante el temor de perder la vida o la propiedad a manos de otro no duda en usar cualquier medio a su alcance. Para evitar vivir en ese estado de vida horrible, embrutecida y breve renunciará a todo derecho a cambio de la protección del Leviatán. "El protego ergo obligo es el cogito ergo sum del Estado". Jean Jacques Rousseau verá lo contrario. El hombre que saquea al vecino o protege violentamente su propiedad es víctima de un orden social injusto. Ha sido pervertido por la codicia o por el resentimiento. Se le ha impuesto un orden social en que el rico tiene tal poder que puede comprar al pobre y este último debe aceptar su venta. Cuando tambalean las instituciones no es rara la revancha de los pobres y el terror de los ricos.

Tras 1810 creímos que entre Hobbes, ideólogo de la monarquía absoluta, y Rousseau, redescubridor de la república clásica, había que optar por el segundo. Tras los luctuosos días posteriores al 27 de febrero del 2010, nuestro convencimiento no es tan firme. Por ello y para evitar caer en la tentación de retornar definitivamente al autor del Leviatán, es bueno buscar orientación en otro debate filosófico que surgió sobre las ruinas de la monarquía.

Tras la derrota de Hobbes, la tradición hegemónica en la civilización noratlántica nos enseña que a partir de las revoluciones liberales de 1776, 1789 y 1810 
la monarquía comenzó a ser reemplazada por la república. Esta última sería una comunidad independiente que se autogobierna o, en los términos más clásicos, gobierno de los muchos en aras del bien común. El ideal de una comunidad de hombres y mujeres libres e iguales en dignidad y derechos sería hijo del liberalismo ilustrado. Para la tradición historiográfica norteamericana dominante hasta la década de los años sesenta del siglo pasado, la revolución de 1776 fue liberal. Es decir, los padres fundadores buscaban crear un orden secular en que sus derechos individuales estuviesen garantizados de todo abuso estatal, máxime si este fuese foráneo. Buscaban la libertad de comercio y un gobierno pequeño que los dejara prosperar según su mérito y esfuerzo personales.

Sin embargo, Hannah Arendt en su libro "Sobre la revolución" se hizo cargo, filosóficamente hablando, de que a partir de 1776 conceptos como virtud y felicidad pública circulaban profusamente; demostrando que otra tradición estaba presente: la republicana (Arendt, 1992; en particular el capítulo cuarto). Cuando republicanos y liberales se enfrentaban a la monarquía absoluta, sus coincidencias eran enormes. Ambas filosofías destacan la importancia de la limitación del poder, en la igualdad y libertad de los ciudadanos y en el papel central del Estado de Derecho. Republicanos y liberales se reconocen como modernos, es decir, creen en la soberanía popular, promueven constituciones escritas, elaboran sistemas electorales que generan novísimas representaciones, y reconocen en el individuo la fuente de toda legitimidad política (Guerra, 2009: 115). Sin embargo, caído el enemigo común las diferencias afloraron.

Anotemos, para fines de este ensayo, tres diferencias centrales ${ }^{3}$ :

- A diferencia del liberalismo que ve en la política un mal necesario, el republicanismo, al igual que la idea democrática, concibe al ser humano como un animal cívico (zoon politikon). Es decir, se parte del supuesto que el hombre y la mujer para desarrollarse plenamente requieren de la comunidad política y de su participación en ella.

- En segundo lugar, lo central para el liberal está dado por las virtudes privadas. El ciudadano cliente o consumidor es un celoso defensor de sus de-

3 Introducciones de este debate pueden encontrarse en Held, 2001 y Rivero, 1998. 
rechos individuales. Por el contrario, el ciudadano virtuoso es el héroe del republicanismo, siempre preocupado de sus deberes para el bien común.

- Por último, contra el universalismo abstracto de los liberales, los republicanos promueven el amor a la patria. Toda sociedad política requiere sacrificios, deberes y disciplinas no despreciables, desde pagar impuestos hasta integrarse a un ejército ${ }^{4}$. En una sociedad libre el aceptar esta carga de restricciones a una libre espontaneidad humana depende no de la coacción sino que de la libre adhesión. Esta adhesión política, para Montesquieu se da por una virtud cívica: el patriotismo, es decir, por "una preferencia continua del interés público sobre el interés de cada cual”.

Este debate historiográfico y filosófico se ha ido trasladando a Hispanoamérica al momento de volver a relatar la historia de las ideas que rivalizaron en 1810 . Bernard Manin nos ha recordado que mientras se gestaba el ideario independentista hispanoamericano dos -y no una- corrientes políticas se desarrollaban con gran vigor: republicanos y liberales. Es cierto que el liberalismo económico inspiró, no sin debates, las demandas de los criollos. Las demandas económicas eran típicamente liberales. Recordemos las cuatro peticiones básicas; comerciar directamente con todos los países, obteniendo así importaciones de las fuentes más baratas; poseer una marina mercante propia e independiente; exportar los productos del país sin restricciones; expansionar la agricultura y la ganadería mediante la distribución de la tierra a condición de que el que la recibiera trabajase la concesión (ver: Lynch, 1976; capítulos primero y décimo). Sin embargo, también eran citados los republicanos herederos de la polis griega y de la civitas romana, quienes se sentían además:

Herederos de Maquiavelo y del humanismo cívico del Renacimiento, quienes ven en la participación en el gobierno de la ciudad la forma más elevada de la realización humana. Su ideal es el del

4 Galston ha propuesto las siguientes virtudes cívicas: a) Virtudes generales: coraje, respeto de la ley, lealtad; b) virtudes sociales: independencia, apertura mental; c) virtudes económicas: ética del trabajo, capacidad de postergar las gratificaciones, adaptabilidad al cambio económico y tecnológico; y d) virtudes políticas: capacidad de reconocer y respetar los derechos de los demás, disposición a no exigir más de lo que se puede pagar, capacidad de evaluar el desempeño de quienes ocupan cargos públicos, disposición a participar en el debate público. Tomado de: Kymlicka y Norman, 1996. 
ciudadano libre e independiente, no sometido a los poderosos ni servil con ellos y capaz de entregarse al bien común, sacrificando de ser necesario sus propios intereses inmediatos, su vida misma, para defender la independencia de una ciudad que se gobierna a sí misma. El ciudadano propietario de su tierra, garantía económica de su independencia, que participa en la vida política y toma las armas cuando la ciudad lo llama, aparece aquí como la figura emblemática (Manin, 2002: 13).

José Antonio Aguilar, cuando intenta explicar la debilidad de nuestros órdenes políticos republicanos, echa mano de este debate. Para el historiador mexicano siempre existieron entre nosotros dos conceptos de república: uno débil y el otro denso (Aguilar, 2002: 57). Hasta hoy nuestra historiografía hispanoamericana no ve en la república sino una forma de gobierno contraria a la monarquía, y se olvida de una concepción más densa y profunda, que provenía de Inglaterra y había echado raíces en Estados Unidos. El punto era fundar y conservar comunidades políticas fuertes, dotadas de autoridad legítima, ciudadanías activas y metas compartidas.

El republicanismo que debimos haber conocido promovía la república "densa", por llamarla de algún modo, que presume la existencia de un Estado libre. Esto es, un cuerpo político autosuficiente conformado por ciudadanos libres, capaces de determinar en forma autónoma sus propios fines. La república perdura gracias a la virtud, definida como la capacidad de cada ciudadano para poner los intereses de la comunidad por encima de los suyos. Para sobrevivir, la república debía mantener ardiendo el espíritu cívico. Conservar una república virtuosa en el tiempo era un asunto muy arduo, pues a cada recodo del camino amenazaba la corrupción. Esta consistía en el egoísmo que apartaba a los ciudadanos de la cosa pública y los sumía en las preocupaciones de la vida privada (Aguilar, 2002: 69).

El lector de este ensayo podrá ver la importancia capital de este segundo debate a la hora de pensar lo ocurrido en el terremoto del 2010. Resulta evidente que una república basada en los derechos individuales y en una concepción epidérmica de los deberes cívicos será mucho más débil a la hora de enfrentar los enormes desafíos que impone el ideal de sentar una comunidad independiente y que se autogobierna, sobre todo en una geografía tan difícil como es la chilena. Para ello 
necesitamos una ciudadanía en la que primen las virtudes públicas propias del republicanismo. De lo que se trata, en circunstancias catastróficas, es que los ciudadanos no cedan a las más elementales de pulsiones de supervivencia personal y de la prole. Más aún, en terremotos y maremotos, los ciudadanos deben ser capaces de promover la solidaridad con los más afectados; actuar como policías cuando el pillaje amenaza; organizar a los vecinos para abastecerse de agua y alimentos; proveerse de los medios para trasladarse y comunicarse con el exterior; etc. En suma, si los ciudadanos de una república quieren ser libres, deben organizarse para ello y enfrentar toda esclavitud, partiendo por el control de las pasiones más disociadoras que nos habitan.

Hay veces que se requiere incluso enfrentarse a la naturaleza, como una vez lo dijo un exaltado Simón Bolívar. Recordemos que un 26 de marzo de 1812, en plena guerra de independencia, un terremoto redujo a ruinas Caracas, Mérida, Barquisimeto, Trujillo y San Carlos. Mientras el libertador trataba de salvar a las víctimas, un pro español llamado José Domingo Díaz, le espetó: “¿Qué tal Bolívar? Parece que la naturaleza ha tomado partido por los españoles". "Si la naturaleza está contra nosotros, pelearemos contra ella y le haremos obedecer”, contestó un furioso Bolívar (Harvey, 2002: 103) La anécdota grafica bien el punto: virtud republicana contra todo evento desgraciado, incluso natural. Sin ella no podríamos ser libres ni prósperos.

\section{CONSERVADORES, REPUBLICANOS Y LIBERALES EN EL CHILE DE 1810}

¿Y qué decir de Chile? Desde sus inicios la historiografía liberal chilena de Miguel Luis Amunátegui, José Victorino Lastarria, Francisco Bilbao, Diego Barros Arana

o Benjamín Vicuña Mackenna señalaron que a partir de 1810 se produjo un quiebre con el pasado y el inicio de una nueva etapa. El fin de un pasado colonial y el inicio de la modernidad liberal. El paso de la monarquía absoluta a la república aristocrática. Por el contrario, otra historiografía de talante conservador, de manos de Alberto Edwards, Francisco Antonio Encina, Mario Góngora y Jaime Eyzaguirre, habría llamado a revisar este relato histórico (ver Jocelyn-Holt, 2009: 17-18). Jaime Eyzaguirre, por ejemplo, arremete en contra de esta concepción 
de la herencia hispánica que sólo veía en ella absolutismo político, despotismo religioso, postración científica y censura filosófico-literaria (Eyzaguirre, 1988).

Eyzaguirre recurre profusamente a la herencia clásica desde Isidoro de Sevilla, del siglo sexto de nuestra era, hasta la doctrina jesuita de Suárez y Mariana, pasando por los municipios hispanos que se autogobiernan en el Medioevo, para demostrar una tradición hispánica no despótica, partidaria del origen popular de la soberanía y del autogobierno, presente en el movimiento revolucionario de 1810 .

$\mathrm{Al}$ debate anterior podemos sumar dos escuelas de pensamiento distintas a las tradicionales, arriba individualizadas. Nos referimos al esfuerzo intelectual de Gabriel Salazar de escribir una historiografía nacional "desde adentro y desde abajo" que desmitifica una memoria histórica enferma, liberal y conservadora, saturada de estatuas y héroes de dudosos ropajes cívicos. Historiografía nacional que ha olvidado a quienes fueron actores colectivos de un intento de desarrollo productivo nacional y no global, fundado en lo local y no en el patriciado metropolitano, y que buscaron ejercer el poder constituyente para establecer una democracia participativa y no una república oligárquica y represiva (Salazar, 2005). Más recientemente aún, Vasco Castillo (2009:9) ha sostenido que ha "intentado demostrar que el republicanismo constituye la principal vertiente que dirige y organiza el pensamiento político del período fundacional, entre los años 1810-1830”. En una línea de pensamiento que, como dijimos en el apartado anterior, va adquiriendo fuerza a partir del debate norteamericano y crecientemente hispanoamericano, las revoluciones de 1776 y 1810 más que liberales, fueron republicanas. Es decir, nuestros "padres fundadores" lucharon por vivir en una comunidad independiente de toda dominación externa y que se autogobernaba, abjurando de toda tiranía y particularismo opresivo.

Para efectos de este ensayo nos interesa este rescate republicano de 1810. Vasco Castillo destaca mucho la importancia del momento republicano en 1810. Para ello recurre a estudiar el pensamiento de algunos de los grandes de ese momento germinal. Nos detendremos en Camilo Henríquez y Juan Egaña.

Para moros y cristianos, Camilo Henríquez es el hombre que dará el paso intelectual decisivo al apropiarse de la tradición republicana de romanos, renacentistas y modernos. Si los hombres querían ser felices, debían ser libres, estando dispuesto cada ciudadano a vencer toda esclavitud. La de los espańoles, franceses o ingleses. 
Pero también la de individuos ambiciosos o grupos facciosos que hiciesen imposible el bien común. Henríquez destacaba, siguiendo a Rousseau, que los antiguos amaban la patria por sobre cualquier cosa, estando dispuestos a morir por ella en la lucha contra el tirano. Amor a la patria,

sentimiento tierno y vivo, que reúne la fuerza del amor propio a toda la belleza de la virtud, le da tal energía, que viene a ser la más heroica de las pasiones. Este fue el principio de esas acciones inmortales, que admiramos en los pueblos ilustres; este fue el móvil de aquellos Generales, de aquellos Magistrados, cuyas antiguas virtudes resucitan en las repúblicas nacientes (...) El amor a la patria es el más enérgico y delicioso de todos los sentimientos; su ardor es siempre sublime, y se aviva y aumenta en medio de las contradicciones. Ya no existía la majestad del pueblo romano, pero Roma vivía siempre en el alma de Catón. Él combate por la libertad y por las leyes con los conquistadores del mundo, y perece bajo las ruinas de la libertad, cuando no existe la patria a quien servía. (Castillo, 2009:23).

Ahora bien, la patria era para el ginebrino el apego a las instituciones políticas que hacían posible libertad o la consagración a una constitución donde los ciudadanos viven como libres e iguales. Para Rousseau "La patria no puede subsistir sin la libertad, ni la libertad sin la virtud, ni la virtud sin los ciudadanos” (Vasco, 2009:24). Henríquez proclamaba el amor a una patria que permitiría a todos los chilenos que "tengan alguna parte, alguna influencia en la administración de los negocios públicos, para que no se consideren extranjeros y para que las leyes sean ante sus ojos los garantes de la libertad civil" (Vasco, 2009:24). Y sin disociar libertad de ley y esta de justicia, agregaba que:

Lo que es aún más necesario, y lo más difícil de existir fuera de las repúblicas, es una integridad severa en hacer justicia a todos y en proteger al débil contra la tiranía del rico. Si la debilidad no está siempre protegida por la fuerza pública resulta un estado sumamente infeliz y que induce la indiferencia por el bien común (Vasco, 2009:24). 
Según Vasco Castillo, Juan Egaña es el otro exponente del pensamiento republicano, que al igual que Camilo Henríquez no teme en remitirse a los clásicos griegos y romanos, junto al moderno Montesquieu (Vasco, 2009:39). Ello lo hace a la hora de promover el amor a la patria y el papel de las leyes, la educación, la milicia y la religión para fundar una república fuerte, grande y virtuosa. Egańa vuelve a interpretar la corrupción como ineptitud para vivir en libertad y el vicio como consagración del interés particular. En 1807 escribía que:

Debemos apartar de nuestros corazones todo sentimiento de interés particular, de crédito y autoridad, esa debilidad tan indigna del amor patriótico como de los grandes héroes. Todo hombre de bien, contento con desempeñar el ministerio que puso la patria a su cargo, no hace crecer su autoridad sino por el nivel de su mérito. Funda su distinción en el respeto que merecen sus acciones, y se concilia aquel homenaje que se debe a la virtud (...) (y prefiere) a todo interés la gloria de su virtud (...), se hace superior a todo interés personal". Y advierte: "Señores, esta gloria se consigue con aquel sincero amor público en que todos los ciudadanos reúnen sus opiniones y deseos". (Vasco, 2009:40).

Don Juan Egaña, citando a Aristóteles y Montesquieu, creía fervientemente en el poder de las leyes para conformar las costumbres. En el manuscrito del proyecto constitucional de 1811, en el artículo 37 titulado "Virtudes y Carácter nacional", lista virtudes que eran fundamentales para el pueblo chileno de aquel entonces:

Todas las virtudes hacen feliz a un estado; pero (la situación de este) pueblo exigen más conato en sostener algunas particulares. Tales son en esta República, el espíritu de fraternidad, y la mutua generosidad en apreciar unos ciudadanos las virtudes y talentos de otros; en radicar un genio laborioso, y dirigir el lujo de los particulares a la felicidad pública. Formado sobre todo como un carácter nacional (...) siendo esto más necesario en los países donde se va a formar el carácter (Vasco, 2009:41). 
Extraña cuando se acusa a Juan Egaña de moralista y utópico por pretender formar ciudadanos virtuosos, echando mano a la ilustración pública y a las leyes. Debatamos el método, pero no la urgencia y necesidad de la finalidad. Hay quienes creen que las leyes sin costumbres no son nada. Hay otros, por el contrario, que afirman las costumbres sin el auxilio de las leyes son palabras vacías y gestos fatuos. Debate de primer nivel de aquellos tiempos, sin embargo, don Juan no divagaba como un mal filósofo acerca de esencias etéreas. Decía verdades prácticas cuando alertaba que todo estaba perdido si el amor a la patria no se anteponía al interés personal. Eso lo afirmaba en medio de una guerra, a ratos fratricida, cuyo desenlace no era nada de claro. Veamos por qué.

Tras la Junta de Gobierno, los partidarios de Martínez de Rozas se habían enfrentado duramente a los moderados. José Miguel Carrera disolvía el Congreso de 1811 y daba un golpe de Estado. Bernardo O’Higgins terminaría combatiendo contra Luis Carrera en el combate de las Tres Acequias, el 26 de agosto de 1814. El desacuerdo entre los líderes revolucionarios llevaría al desastre de Rancagua. Los asesinatos de los hermanos Carrera y Manuel Rodríguez son parte de esta abierta lucha fratricida. El renegado suboficial chileno Vicente Benavides recibía apoyo no sólo de los españoles del Perú, sino que también de los chilenos de Valdivia y Chiloé. Ramón Freire, hermano de armas de Bernardo O'Higgins en Rancagua, se sublevará contra un patriciado santiaguino que no aportaba nada para mantener la economía y el ejército del sur, desolado por la "guerra a muerte" y diez años de hambruna en la provincia de Concepción (Seguimos a Salazar, 2005: 495-507).

Veamos pues que llegó un momento, cuando la naciente república daba sus primeros pasos, en que el bajo pueblo de las provincias dudaba bajo los sufrimientos del hambre y del frío. Los chilenos más acomodados sufrían los rigores de requisiciones y expropiaciones continuas, más la muerte de sus mejores hijos. Parte del clero se mantenía fiel a Roma y a la monarquía, mientras que la otra adhería a la república. Los chilenos realistas de Valdivia y Chiloé se enfrentaban a muerte con los patriotas del Valle Central y Concepción. Nuestros jefes militares se dividían hasta llegar a las manos y a las armas en cuestiones dramáticas como financiar la escuadra libertadora al Perú o el aprovisionamiento de la provincia de Concepción. Los republicanos temerosos de los excesos de la participación popular reclamaban un orden aristocrático ante los más radicales que pedían la democracia. 
Facciones se formaban; pipiolos y pelucones se motejaban. Clases sociales enfrentadas; provincias divididas; ejércitos rivales; Iglesia y Estado recelosos uno del otro; comerciantes y productores locales agobiados y recelosos de militares y políticos. iiEsto en medio de una guerra a muerte contra el ejército espańol!!

La república ya no aparecía como dulce orden civil; justicia para todos; igualdad ante la ley; los muchos gobernando en aras del bien común. Nada de ello. Los privilegiados de siempre azuzando con malicia a una masa iletrada, cuyo pecado era la ignorancia. Ganoso el pueblo con la libertad experimentada, rápidamente hecha licencia, vicio y corrupción. Asambleas ruidosas, facciones desatadas en su pugna por el poder y guerra civil en que todo exceso, violencia, abuso y desprecio del interés general eran permitidos. El riesgo era evidente: que la propia nación chilena, si es que había tal cosa, terminase llamando nuevamente al monarca español o, peor aún, al tirano. Es el momento del lamento adolorido de Ramón Freire. Recuérdense sus palabras:

Debo a mi patria, a mi familia, a mi conciencia... a esa nación convertida hoy en víctima i juguete de una facción hipócrita i fratricida... En las filas en que he combatido se hallan todos los chilenos de probidad, de luces i de honor; todos los que no han respirado el aire mefítico de la facción. (Salazar, 2005: 508).

Egaña y Henríquez sabían del riesgo que se corría. La historia enseñaba, los clásicos lo decían, que muchas revoluciones se habían hecho desde los tiempos del libertario Espartaco o el reformista alemán y líder de los campesinos medievales alemanes Thomás Müntzer. Pero muy pocas habían vencido. Mas sus verdugos no habían sido generalmente los liberticidas de siempre, sino que ellas habían caído derrotadas, como lo recordaba Camilo Henríquez en El Monitor Araucano, por "el peso de la desunión, de la ambición, del interés, y de la cobardía" (Castillo, 2009:53). Esas eran las pasiones que empezaban a gobernar los corazones de los patriotas de 1810.

¿Qué hacer? ¿Recurrir al dictador, como lo hacían los romanos y Simón Bolívar lo haría en Venezuela, Colombia y Perú? ¿Retroceder un paso, aprender de la revolución inglesa y darnos un monarca vitalicio y constitucional, electivo quizás? ¿o era una posibilidad que José de San Martín, patriota resuelto, propuso para sal- 
varnos de la anarquía? ¿Aprender la lección norteamericana, darnos un presidente con poderes muy contrabalanceados por los tribunales de justicia, Congreso y estados federales?

Me interesa destacar tres remedios que propusieron los republicanos originarios. Constitución política, educación pública y medios de comunicación libres. Ellos serían los encargados de promover los ciudadanos virtuosos que en situaciones tan extremas estarían dispuestos a cumplir con sus deberes y servir al interés general, aun a costa de sus derechos individuales y seguridades vitales. Insistamos que Don Juan Egańa no era un tonto moralista ni un utópico soñador. Sabía con Don Camilo Henríquez que "un Pueblo sin Constitución es un grupo de infelices dejados al capricho y a la intolerancia del poder físico" y en que el derecho del oprimido será resuelto mediante violencia y turbulencias que traerían la ruina irreparable de la Patria (Castillo, 2009:67).

Camilo Henríquez propone para fortalecer la república "La Aurora de Chile" y "El Monitor Araucano". La Aurora de Chile la fundó para que empezara a desaparecer "nuestra nulidad política" (Castillo, 2009: 36). Para que existan Estados libres necesitamos ciudadanos instruidos en las ciencias del gobierno y en la economía política. Para ello existe la libertad de imprenta y los periódicos. Afirma que solo en Nueva York se publican diariamente siete (Castillo, 2009:35). Las tiranías se encargan de mantener al pueblo en la ignorancia y en el embrutecimiento. Por el contrario, la república promueve la ilustración del pueblo, decirles la verdad, promover los principios y condenar errores, prejuicios y mentiras. Por ello sostiene que:

De aquí es que los periódicos, o papeles públicos, de los pueblos libres son la verdadera historia del tiempo presente; describen con ingenuidad los sucesos adversos y los prósperos; presentan los clamores de los oprimidos, el estado bueno o malo de las rentas públicas, de la educación, de los ejércitos, de la marina; advierten al Gobierno de lo que debe recelarse, de lo que debe promover, de lo que debe presumir; transcriben los debates y dictámenes, o sensatos o disparatados, de los miembros de la Legislatura. Al tiempo que, "por el contrario, los periódicos de los países esclavos son una coor- 
dinación de mentiras para mantener la ilusión del pueblo, y nunca le hablan de lo que más le interesa saber" (Castillo, 2009:38).

Por su parte, para promover las virtudes públicas, Don Juan Egaña propone que en el orden constitucional se consagre el deber del Estado de garantizar la instrucción pública. En el Proyecto de 1811, Egaña expone que:

los Gobiernos deben cuidar de la educación en institución pública como una de las primeras condiciones del pacto social. Todos los Estados degeneran y perecen a proporción que se descuida la educación y faltan las costumbres que la sostienen y dan firmeza a los principios de cada Gobierno. En fuerza de esta convicción, la ley se contraerá especialmente a dirigir la educación y las costumbres en todas las épocas de la vida del ciudadano (Artículo 36).

Ello se hace realidad en el Instituto Nacional. En el proyecto constitucional de 1811 se lee: "Se establecerá en la república un gran Instituto Nacional para las ciencias, artes, oficios, instrucción militar, el carácter físico y moral del ciudadano. Este será el centro y modelo de la educación nacional, la gran obra" al cuidado y protección de las Instituciones del Estado (Castillo, 2009:45).

Sin duda alguna ya no podemos creer, con la ingenuidad auroral de Egaña y Henríquez, de la bondad y eficacia de la educación pública, los medios de comunicación social y de las constituciones políticas. Pero, por otro lado, las insuficiencias de la democracia liberal representativa han llevado a un renacimiento del ideal republicano y de la preocupación por crear instituciones que promuevan las virtudes públicas (Ovejero, 2003:11-58). Sin Estados con capacidad de hacer respetar la ley, no hay paz mundial, seguridad interna y crecimiento económico 5 . Los Estados son vitales para los países que están lejos de los grandes centros comerciales mundiales, cuentan con geografías difíciles que aumentan los costos de transporte externo e interno, de la agricultura y de la salud por la ecología de sus enfermedades $^{6}$. Del mismo modo, hay ya mucha literatura acerca del capital social que nos

5 Acerca de la importancia del Estado para garantizar la paz mundial y la seguridad interna recomendamos Fukuyama, 2007 y 2004.

6 Acerca de la importancia del Estado en países con geografías difíciles ver: Sachs, 2006: 99 -101 y 136-137. 
demuestra que este es fundamental a la hora de diferenciar pueblos desarrollados de los que no lo son. Además sabemos también modos de promoverlo, que incluyen la ley en Finlandia y la educación pública en Inglaterra (Atria y Siles, 2003).

Es cierto que Juan Egaña y Camilo Henríquez promovieron las virtudes públicas para enfrentar los desastrosos efectos de una guerra sangrienta e intestina. Entre 1811 y 1826 la lucha por la independencia nacional fue especialmente ruinosa en el sur de Chile. Sin embargo, es evidente que sus reflexiones son plenamente aplicables a un pueblo que ha nacido en tierra de volcanes y terremotos. No es raro que, como un triste y monumental recordatorio, la naturaleza haya vuelto a rugir en las tierras de 1810. Chile es tierra de volcanes y terremotos que, cuando se enojan, no dejan piedra sobre piedra. La historia demuestra cómo ese pueblo tan golpeado, siempre se ha levantado y empezado de nuevo. Pero son enormes los esfuerzos mancomunados que hay que canalizar y los gastos que hay que irrogar. Para graficarlo es bueno recordar la historia de Concepción.

\section{LA HISTORIA DE CONCEPCIÓN Y LA NATURALEZA CHILENA "HEROICO-TRÁGICA"}

Quiero detenerme un momento en relatar lo ruinosa que puede ser nuestra naturaleza. Me gustaría mostrar imágenes de lo que queda tras un terremoto. No lo puedo hacer, pero sí mostrar la historia de la provincia de Concepción. Partiré recordando a Gabriela Mistral y sus palabras ante el terremoto de $1939^{7}$. Con el alma partida, desde un pueblo español de la Florida, San Agustín de Ponce de León, Gabriela Mistral relató el terremoto de Chillán, el de 1939. Agobiada por las noticias que le llegaban decidió enviar un recado, con "rumbo y al azar", a los amigos de América. Pedía solidaridad con su pueblo, a los que la conocían y a los que no. En dicha carta explicaba que "La naturaleza chilena es heroico-trágica". Esa fuerza telúrica había destrozado varias veces la provincia de Concepción. Se le partía el alma pues Gabriela Mistral, siete meses atrás apenas, había estado en Chillán. Había ido en búsqueda de la vieja chilenidad, el Chile clásico. Allí tres mil nińos chillanejos, "sana mocería criolla", habían desfilado en su honor. Ahora

7 Se trata del escrito de Gabriela Mistral "La tragedia andina: recado para los amigos de la América (1939)"; ver Quezada, 2004. 
una porción de esa "carne niña" había pasado en una noche de fábula directamente al sueño eterno. La poetisa continuaba señalando que "Lo catastrófico que llena las planas de los diarios de América, no ha sido, por desgracia, exagerado. Un tercio del territorio quedó dentro de la conmoción y las mejores ciudades de la zona, logradas a fuerza de civilidad corajuda, han padecido quebranto ligero o mortal. Pero Chillán, cuna de nuestro O’ Higgins esencial, fue realmente arrasada y hay que levantarla piedra a piedra; y la ilustre Concepción, santo y señor del Sur, de tan noble estampa, ha perdido barrios enteros y deberá reedificarse en buena parte”. ¿Podríamos hacerlo? La historia ha dicho siete veces que sí.

Ello se demuestra con la historia de Concepción (Schneider, 1950: 452 y ss). Fundada el 5 de octubre de 1550, ya el Miércoles de Cenizas del 8 de febrero de 1570, a las nueve de la mañana, un terremoto destruyó todas las iglesias, edificios públicos y casas. Nadie se podía tener en pie. Grandes grietas se abrían en el suelo, por las cuales salían humo y agua. Góngora y Marmolejo dice que sus habitantes creían que "el mundo se acababa". Y el 15 de marzo de 1657 un maremoto lo volvió a destruir todo. El mar se recogió de la orilla formando gigantescas olas que cayeron como un trueno maldito sobre los escombros de la ciudad. Un barco, al día siguiente, apareció cerca de la actual plaza de armas de Penco. Nuevamente tuvimos un maremoto en 1730, el 8 de julio a las cuatro de la mañana, generándose tres gigantescas olas que destruyeron las doscientas casas que conformaban la vieja ciudad. Concepción fue trasladada al Valle de La Mocha, tras el terremoto del 25 de mayo de 1751, pues el terremoto y posterior maremoto "no dejó en sus sitios sino muy pocas piedras" como observó un cronista de la época.

La república no se salvó del flagelo. Lo peor fue la "gran ruina" del terremoto y maremoto del 20 de febrero de 1835. Las torres de la catedral se vinieron abajo. Olas de quince metros reventaron en Talcahuano. El 4 de marzo, entraba a la bahía de Concepción el barco inglés "Beagle", con Carlos Darwin entre sus tripulantes. Escribió en su diario:

Se siente algo de aflictivo y de humillante al mismo tiempo, viendo estas obras que han costado tanto trabajo y tanto tiempo, destruidas, así, en un minuto (...) En mi concepto, desde que salimos de Inglaterra, no habíamos visto contemplado espectáculo conmovedor como éste (Schneider, 1950: 454 y 456). 
El 13 de agosto de 1868, desde la Antártica hasta California y desde Australia hasta Chile, el mar volvió a mostrar su poder. En Talcahuano, a las 20.15 horas, la marea subió paulatinamente amenazando la Aduana. Una hora más tarde se retiró una cuadra y media, dejando seco el islote de la viuda. Minutos más tarde, con "un rugido espantoso", avanzó una ola enorme, que llegó hasta la misma Plaza de Armas, arrastrando todo tras de sí: muelles, pescantes, embarcaciones y edificios" (Schneider, 1950: 457). ¿Suficiente? No, la naturaleza hizo sentir su fuerza con fuertes temblores en 1898, 1906 y 1907 (Schneider, 1950: 458).

El siglo veinte no fue menos cruel. Un terremoto grado 9 se produjo el 24 de mayo de 1939. Nadie podía sostenerse en pie. El 80\% de las casas enroladas se vinieron abajo. Miles de penquistas murieron. Se calculan los muertos en treinta mil, siendo fundamentalmente afectada la ciudad de Chillán. Antes del amanecer del sábado 21 de mayo de 1960, a las 06:06, un fuerte sismo sacudió gran parte del sur de Chile: Concepción y Talcahuano incluidos. El primer movimiento telúrico produjo el derrumbe del puente carretero sobre el río Biobío. A las 6:33, un segundo movimiento se produjo y derrumbó las construcciones deterioradas por el primer terremoto. Concepción quedó incomunicado, las cañerías de agua potable se destruyeron y los tendidos eléctricos se cayeron provocando incendios. Lo peor se viviría en Valdivia, produciéndose el peor terremoto del que se tenga registro en la historia de la humanidad. Finalmente, el siglo XXI acaba de inaugurarse con un terremoto grado 8,8 que ha causado enormes daños a la provincia de Concepción y a la zona central de Chile.

A pocos días de producido el terremoto del bicentenario recibí el siguiente correo de un colega abogado de Concepción que me decía "Ayer nos reuníamos para salir a tomar un copete a algún pub o casino. Hoy día damos gracias a Dios por tomar un vaso de agua, sin cuestionar su origen". Tras describir sus tres horas haciendo cola en la villa para comprar lo que se pueda, recuerda cómo dos centros comerciales fueron saqueados. "De manera completa, metódica y absoluta. A plena luz del día. Todo, se llevaron hasta las mascotas de la tienda. Todo". En el centro mismo de la capital regional le "tocó asistir, a plena luz del día, al saqueo de tiendas de golosinas (distribuidoras), supermercados, tiendas de muebles, bodegas de Ripley, Falabella, y otras, con personas de toda clase social, con tantos vehículos que cortaron el tránsito en calle Los Carrera, en sus seis pistas. 
Un igualitarista de los albores de la república chilena no dudaría en decirle a mi amigo que lo que relata es fruto maldito de las desigualdades existentes en Chile. Se me viene a la memoria una carta que Santiago Arcos le dirigió a Francisco Bilbao, el 29 de octubre de 1852. Escribe, desde la cárcel de Santiago, en contra del orden establecido tras la Independencia. Abomina ese Chile en el cual hay "cien mil ricos que labran los campos, laborean las minas y acarrean el producto de sus haciendas con un millón cuatrocientos mil pobres". En tal desigual e injusta sociedad, Santiago Arcos dice que "los rotos, plebe en las ciudades, peones, inquilinos, sirvientes en los campos” por mucho que se esfuercen y junten capital jamás serán bienvenidos entre los ricos (Godoy, 1971). Ante este cuadro social, Arcos le dice a Bilbao que las instituciones y las leyes son malas pues imponen un orden político injusto en que los ciudadanos no tienen garantía constitucional alguna. Lo que mantenía el orden era la fiereza brutal de la clase gobernante. Pero si ésta llegase a faltar, vendría la anarquía. "Así el país vivirá siempre entre dos anarquías: el estado de sitio, que es la anarquía a favor de unos cuantos ricos; y la anarquía, que es el estado de sitio a favor de unos cuantos pobres”.

Me quedan resonando estas palabras. No quiero justificar nada, pero sí intentar comprenderlo todo. No puede ser que nuestro Estado de Derecho sea así de vulnerable en medio de una catástrofe, por grande que sea. Caídas las instituciones regulares, los vecinos de Concepción, Talcahuano, Lota, Quilicura, por mencionar algunas comunas, son sometidas a la anarquía del pillaje de la turbamulta y a la imposición, en los hechos, de un arresto domiciliario terrorífico. Los temores sociales se encienden. Se decía que los vecinos de un barrio de profesionales de San Pedro de la Paz serían asaltados por los pobres y cesantes de Lota y Coronel. Los habitantes de un pasaje de Cerro Navia son alertados que los temibles vecinos de ciertas poblaciones de Renca afilan sus hachas. Y no hay más solución inmediata que la autodefensa vecinal y pedir a gritos que se decrete toque de queda y que los militares salgan a la calle. Bien que se haya hecho, pero... ¿eso sería todo?

Santiago Arcos no se sorprendería. Su solución sigue siendo válida: "Queremos asegurar la paz por el único medio eficaz, haciendo que las instituciones sean el patrimonio de cada ciudadano y estén en armonía con intereses de una fuerte mayoría” (Godoy, 1971). Creíamos haberlo logrado. Mucho hemos avanzado desde 1852. Pero parece ser que hay chilenos que no lo entienden así y lo hicieron ver con salvajismo esos días. 
Sin embargo, con todo lo dicho, republicanos a lo Juan Egańa y Camilo Henríquez sólo coincidirían en parte con Don Santiago. Los republicanos, tanto los que hicieron su hogar en el bando conservador como los más radicales, no estarían plenamente conformes con la explicación de Arcos. Es cierto que cuando los débiles no están bien protegidos por la fuerza pública, cunde la infelicidad y la indiferencia por el bien común. Sí, pero qué decirles a quienes vieron saqueos realizados desde vehículos de elevado valor. Filas de autos saqueando. ¿Por qué esos conductores no se fueron a poner a disposición de la Intendencia o de la Municipalidad para ayudar al compatriota? Pues los republicanos saben que siempre y en cualquier lugar debe amarse la patria. Ella es la libertad y las leyes, diría don Juan Egaña. Como dijimos, virtud pública que nos llama a realizar esa "disposición generosa de sacrificar su interés personal al interés universal del pueblo".

Amar a Chile es fácil cuando se es acomodado y se vive en circunstancias de normalidad. Lo difícil es cuando se es pobre o, caído el Estado de Derecho, surge el miedo a perderlo todo. Pues lo difícil es hacer valer la libertad del republicano frente al aspirante a tirano, sea uno en el palacio de gobierno o miles en las calles. Patriotismo de los jueces, carabineros, soldados y funcionarios públicos que hicieron triunfar la ley en febrero del 2010, apresando al perturbador de la quietud cívica y reponiendo el orden público. Patriotismo de esos vecinos que, venciendo el miedo, partieron a ayudar a los más desvalidos. Patriotismo de esas paramédicos, doctoras y enfermeras que cruzaron a pie el puente sobre el Biobío para ir a atender a sus enfermos, para no dejarlos desamparados; dejando solas sus casas. Patriotismo del médico que, en bicicleta, sabía muy bien en qué consistía su deber. Patriotismo de esos jóvenes voluntarios que salieron a recoger alimentos no para ellos, sino que para los otros. Patriotismo de los comunicadores sociales que no infundían alarma ni rabia, sino que tranquilidad y solidaridad. Patriotismo de esos bomberos, voluntarios por cierto, que arriesgaban su vida escarbando escombros en busca de esperanza. Patriotismo de Marcela del Carmen Torres, pobladora de Hualpén de 37 años, que lloraba avergonzada ante el conductor de televisión diciendo que ella y su hija tenían necesidad, pero que no participarían en ningún saqueo. Reclamó que su condición de cristiana le impedía hacerlo y la esperanza le decía que "No faltará". Patriotas que no tenían que esperar ayuda de nadie ni recibir instrucciones de ninguna autoridad para cumplir con su deber. 
Sin esos patriotas, Camilo Henríquez diría que "estamos condenados a ser esclavos eternamente". No hay república sin republicanos y no hay libertad sin hacer lo que se necesita para ser libres. Eso es lo que los republicanos llaman patriotismo. A Dios gracias eso también existió anónimamente, todos esos angustiosos días posteriores al terremoto del bicentenario, en la provincia de Concepción y en Chile entero.

\section{A MODO DE REFLEXIÓN FINAL: VIRTUDES REPUBLICANAS EN TIERRA DE VOLCANES Y TERREMOTOS}

En apretada síntesis podemos concluir que el terremoto del bicentenario nos recordó que no podemos ser ingenuos acerca de la condición humana cuando se trata de edificar nuestras instituciones públicas. Terminan haciéndole el favor a las peores reacciones conservadoras visiones de seres humanos naturalmente buenos, generosos y altruistas. Cuando en circunstancias trágicas resurge el conato existencial, el deseo de seguir viviendo, y la defensa de lo propio, no nos podemos hacer ilusiones acerca de la condición humana;

Del mismo modo es posible señalar que, si hay algo que nos enseña el debate entre republicanos y liberales de 1810 es justamente la importancia de recurrir a la cultura para promover virtudes públicas. No es ingenuidad ni utopismo, sino que frío realismo. El contar con instituciones públicas asentadas en una poderosa Constitución política, legítima ante la comunidad nacional, y promover las virtudes públicas mediante la educación y los medios de comunicación social, es vital. Juan Egańa y Camilo Henríquez no ahorraron tinta y trabajo en esa línea.

Del mismo modo cabe destacar que lo dicho es especialmente importante en tierra de volcanes y terremotos. Sé que nos quedamos cortos con la metáfora pues podríamos agregar a volcanes y terremotos, maremotos, sequías e inundaciones bastante predecibles en el futuro por el cambio climático. Sumemos a ello nuestra lejanía de los grandes centros mundiales y una loca geografía de desiertos en el norte, cordilleras inmensas en el oriente, mares siderales por el occidente y hielos por el sur. Inglaterra y Estados Unidos crecieron económicamente, entre otras razones, por su ubicación geográfica y fertilidad de sus tierras. El propio Adam 
Smith lo reconoció así (Sachs, 2006: 100). Los que deben luchar en contra de ella, requieren aún más cooperación y esfuerzo, ese que deben canalizar las instituciones públicas, el capital social y el Estado. La debilidad del Estado chileno desnudado el 27 de febrero del 2010, oficinas de emergencia y fuerzas armadas incluidas, nos recordaron amargamente esta verdad; y Finalmente, las modernas teorías de la cohesión social demuestran la importancia que esas instituciones públicas, llamadas a gobernar en tan difíciles situaciones como fue el terremoto del bicentenario, requieren no sólo contar con los recursos adecuados, gestiones eficaces y eficientes, sino que con la enorme legitimidad que dan los valores, afectos y esfuerzos compartidos. No reclamemos que el injustamente tratado actúe como un abnegado patriota cuando su tierra está en peligro. Los terremotos de Nicaragua en 1972 y México en 1985 demostraron lo corruptas que estaban sus instituciones, acelerando revoluciones o cambios de regímenes políticos (ver Mc Adam, Tarrow y Tilly, 2005: 220 y 327). Santiago Arcos nos recordaba desde la cárcel que la ley, para ser tal, debe ser justa.

\section{REFERENCIAS BIBLIOGRÁFICAS}

Aguilar Rivera, José Antonio (2002). “Dos Conceptos de república”, en José Antonio Aguilar y Rafael Rojas (coordinadores) El republicanismo en Hispanoamérica. México: Fondo de Cultura Económica.

Arendt, Hannah (1992). Sobre la revolución. Madrid; Alianza Universidad.

Atria, Raúl y Siles, Marcelo (2003). Capital social y reducción de la pobreza en América Latina y el Caribe: en búsqueda de un nuevo paradigma. Santiago: CEPAL.

Castillo, Vasco (2009). La creación de la república. Santiago: LOM.

Delumeau, Jean (2002). El miedo en Occidente. Madrid: Taurus.

Eyzaguirre, Jaime (1998). Ideario y ruta de la emancipación chilena. Santiago: Editorial Universitaria. Fukuyama, Francis (2004). La construcción del Estado. Buenos Aires: Ediciones B.

Fukuyama, Francis (2007). América en la encrucijada. Barcelona: Ediciones B.

Godoy Arcaya, Oscar (1986). "Selección de escritos de Thomas Hobbes" en, Revista de Estudios Públicos; $\mathrm{N}^{\circ} 23$. 
Godoy, Hernán (1971). La estructura social de Chile. Santiago: Editorial Universitaria.

Goodwin, Bárbara (1997). El uso de las ideas politicas. Barcelona: Península.

Guerra, Francois-Xavier (2009). Modernidad e independencias. Madrid: Encuentro.

Harvey, Robert (2002). Los libertadores; Barcelona: Océano.

Held, David (2001). Modelos de democracia. Madrid: Alianza.

Jocelyn-Holt, Alfredo (2009). La Independencia de Chile. Santiago: Random House Mondadori.

Kymlicka, Will y Norman, Wayne (1996). "El retorno del ciudadano. Una revisión de la producción reciente en teoría de la ciudadanía". En, Revista La Política N³.

Lynch, John (1976). Las revoluciones hispanoamericanas: 1808-1826. Barcelona: Ariel.

Manin, Bernard (2002)."Montesquieu, la república y el comercio", en José Antonio Aguilar y Rafael Rojas, (coordinadores) El republicanismo en Hispanoamérica. México: Fondo de Cultura Económica.

Mc Adam, Doug, Tarrow, Sidney y Tilly, Charles (2005). Dinámica de la contienda social; Barcelona: Editorial Hacer.

Miranda, Carlos (1997). “Antología política de Rousseau” en, Revista de Estudios Públicos N65.

Ovejero, Félix; Martí, José Luis; Gargarella (2003). Nuevas ideas republicanas. Autogobierno y libertad. Barcelona: Paidós.

Quezada, Jaime (compilador) (2004). Gabriela Mistral: Pensando a Chile. Una tentativa contra lo imposible. Santiago: Comisión Bicentenario.

Rivero, Ángel (1998). “El discurso republicano” en, Rafael Del Águila, Fernando Vallespín, y otros, La democracia en sus textos. Madrid: Alianza Editorial.

Sachs, Jeffrey (2006). El fin de la pobreza. Buenos Aires: Editorial Debate.

Salazar; Gabriel (2005). Construcción de Estado en Chile. Santiago: Editorial Sudamericana.

Schneider, Carlos Oliver (1950). Libro de oro de la historia de Concepción.

Strauss, Leo, y Cropsey, Joseph (Compiladores) (1996). Historia de la filosofía politica. México: Fondo de Cultura Económica.

Taylor, Charles (1997). Argumentos Filosóficos. Barcelona: Paidós.

Withington, John (2009). Historia mundial de los desastres: Crónicas de guerras, terremotos, inundaciones y epidemias. Madrid: Turner. 